\title{
GENETIC VARIABILITY OF EUGLENA AGILIS (EUGLENOPHYCEAE)
}

\author{
BOŻENA ZAKRYŚ ${ }^{1}$, JOANNA EMPEL ${ }^{2}$, RAFAŁ MILANOWSKI ${ }^{1}$, \\ Robert GromadKa ${ }^{3}$, PiOTR BorsuK ${ }^{2}$, MARTA KęDZIOR ${ }^{1}$, JAN KWIATOWSKi ${ }^{1}$ \\ ${ }^{1}$ Department of Plant Systematics and Geography, Warsaw University \\ A1. Ujazdowskie 4, 00-478 Warszawa, Poland \\ e-mail: zakrys@biol.uw.edu.pl \\ 2 Department of Genetics, Warsaw University \\ Pawińskiego 5A, 02-106 Warszawa, Poland \\ ${ }^{3}$ Institute of Biochemistry and Biophysics, Polish Academy of Science \\ Pawińskiego 5A, 02-106 Warszawa, Poland
}

(Received: March 8, 2004. Accepted: June 8, 2004)

\begin{abstract}
The results of the internal transcribed spacer (ITS2) of extrachromosomal rDNA and the chloroplast SSU rDNA sequence analysis presented here confirmed elevated genetic polymorphism revealed earlier by RFLP and RAPD for seven clones of the cosmopolitan species - Euglena agilis Carter. High diversity among these clonal strains was not reflected by morphological criteria, with the exception of the only one character - the ability of the cell in its non-motile dividing states (palmella) to produce mucus and form a slimy envelope. Evolutionary adaptation as formation of slimy envelope may be attributed to different survival strategy of the species by which it adapts to life in a highly variable environment.
\end{abstract}

KEY WORDS: Euglena, Euglena agilis, Euglenida, 16S rDNA, ITS2, phylogeny, molecular systematics, taxonomy.

\section{INTRODUCTION}

Until very recently, all practice of distinguishing and identifying euglenoid species was based on morphological criteria, usually revealed by light microscope. Given large morphological plasticity of euglenoids, there is a need of verification of diagnostic morphological characters, because phenotypic diversity, reflecting perhaps adaptations to different environmental conditions or/and particular physiological state of the organism, may not correspond well to genetic variability.

In spite of intensive molecular research into euglenoid diversity, almost all effort is concentrated on the phylogeny of the entire group, its green or colorless forms, or the whole genera, rather than particular species (Thompson et al. 1995; Mountegut-Felkner and Triemer 1997; Linton et al. 1999, 2000; Preisfeld et al. 2000, 2001; Leander and Farmer 2000, 2001a, 2001b; Leander et al. 2001; Milanowski et al. 2001; Moreira et al. 2001; Müllner et al. 2001; Busse and Preisfeld et al. 2002a, b, 2003; Nudelman et. al. 2003; Morin et al. 2003). Few works using combined molecular and morphological approach may be found in the literature dealing with taxonomic subjects on the intra- or inter-specific level, even though, this may yield a practical results helping identifying particular taxa. We have used such an approach with respect to three Euglena species: E. agilis Carter (Zakryś and Kucharski 1996; Zakryś et al. 1996; Zakryś 1997, 1997a), E. gracilis Ehr. (Zakryś et al. 1997) and E. geniculata Duj. (Zakryś et al. 2002). Only in the last case the sequence analysis was used (16S, $18 \mathrm{~S}$, ITS2), while the two first dealt with analysis of fragment lengths (RAPD and RFLP).

The most unexpected results were obtained for E. agilis (Zakryś and Kucharski 1996; Zakryś et al. 1996). Genetic polymorphism sampled by RFLP and RAPD analysis revealed high diversity among 12 clonal strains, which was not reflected by morphological criteria, with the exception of the only one character - the ability of the cell in its nonmotile dividing states (palmella) to produce mucus. On the basis of these findings a taxonomic revision of the entire group consisting of fourteen variations and four species, all with similar morphology to Euglena agilis, was proposed. We thus concluded that all diversity should be contained within the single taxon - E. agilis Carter (Zakryś 1997). The difference in the ability to produce a mucilage layer by palmelloid stages was not taken into account then, because 
we felt that this may not be done without further insight into genetic diversity by sequence analysis approach. This approach is used herein. We believe that this approach should help defining the concept of euglenoid species, as well as, at the practical level, be helpful in devising clear criteria to identify taxa in the genus Euglena. So far, the existence of numerous so called critical groups of species (similar morphologically), as well as the lack of consensus on which morphological characters should be considered diagnostically important are causing a considerable difficulty in identifying euglenoid species.

\section{MATERIAL AND METHODS}

\section{Euglenoid strains and culture conditions}

All strains were cultivated in liquid soil-water medium, enriched with a small piece of garden pea (medium 3c, SAG Göttingen; Schlösser 1994). Seven clones of E. agilis, isolated in 1992-1993 from different localities in Poland (Zakryś et al. 1996), the same that were used for RAPD and RFLP analyses (Zakryś and Kucharski 1996; Zakryś et al. 1996) were used in this study. With respect to the mucus production three types of strains were identified by localities from which they came: Wisła k-1 (Wi),Wąwocko k-1 (Wa) (substantial mucus); Kołczewo k-1 (Ko), Pruszków k-1 (Pr) (minute mucus); Górki k-3 (Go), Piaski k-1 (Pi), Nowy Targ k-1 (NT) (no mucus).

\section{DNA Isolation, amplification and sequencing}

Isolation of DNA, amplification, purification of PCR products and sequencing of chloroplast SSU and ITS2 rDNA was performed as previously described (Milanowski et al. 2001; Zakryś et al. 2002). The GenBank accession numbers for SSU and ITS2 rDNA sequences reported in this paper are shown in Table 1.

\section{Sequence alignment and phylogenetic analysis}

The sequences used for phylogenetic analyses are shown in Table 1. Alignment of sequences was obtained using the Clustal X program (Thompson et al. 1994; Thompson et al. 1997) with default options, manually checked and edited according to the secondary structure of Euglena gracilis
16S rRNA as suggested by Van de Peer et al. (1999). Regions, which could not be unambiguously aligned, were omitted from analyses. The alignments used for analyses are available in EMBL [alignment 16S: ALIGN_000698; alignment ITS2 agilis + gracilis: ALIGN_000699; alignment ITS2 same agilis: ALIGN_000700]. The address of EMBL is: ftp: //ftp.ebi.ac.uk/pub/databases/embl/align/. The 16S as well as ITS rDNA trees were built and their stability assessed by posterior probabilities using Bayesian inference (Huelsenbeck et al. 2001) and general time reversible model (GTR + I + G) (Tavaré 1986; Yang 1993), with the rates of nucleotide substitutions, the base frequencies, the shape of the gamma distribution and the proportion of invariant sites estimated, as implemented in MrBayes 2.01 program (Huelsenbeck and Ronquist 2001). The sequences of Euglena subgenus were used for comparison and as an outgroup for $16 \mathrm{~S}$ rDNA, while E. gracilis sequence was an outgroup for the ITS2 trees. The trees were drawn by Tree View, Version 1.6.1 for Microsoft Windows (Page 1996).

\section{RESULTS}

Phylogenetic analysis of 16S rDNA from several euglenoid species show that the sequences of all three E. agilis clones form a well defined clade with $E$. gracilis as a sister group (Fig. 1). The branching order between the three clones, representing different levels of mucilage forming, could not however be established. The distances between the three groups are in the range of the distances between two of the most divergent clones of E. geniculata.

In order to further assess the genetic similarity of the $E$. agilis clones, we have surveyed the fragment of extrachromosomal DNA for large subunit (LSU) rRNA species 1 and 2, encompassing the part corresponding to 5.8 S rRNA, ITS2 and the beginning of 28S rRNA (Schnare et al. 1990). We have sequenced this region in seven clones of E. agilis, isolated in 1992-1993 from different localities in Poland, the fraction of the same clones that were used for RAPD and RFLP analyses (Zakryś and Kucharski 1996; Zakryś et al. 1996). Unequivocal alignment of all the sequence fragments used for analysis could only be done within the re-

TABLE 1. GenBank accession numbers, culture, and collection information for members of the genus Euglena used in this study. Accession numbers of sequences obtained in this study are printed in bold.

\begin{tabular}{|c|c|c|c|}
\hline \multirow{2}{*}{ Taxon } & \multirow{2}{*}{ Strain } & \multicolumn{2}{|c|}{ GenBank accession number } \\
\hline & & 16S rDNA & ITS2 \\
\hline Euglena agilis Carter & UW Górki k-3 & & AY158149 \\
\hline Euglena agilis Carter & UW Piaski k-1 & & AY158147 \\
\hline Euglena agilis Carter & UW Nowy Targ & AY158150 & AY158148 \\
\hline Euglena agilis Carter & UW Wąwocko k-1 & AY158151 & AY158144 \\
\hline Euglena agilis Carter & UW Wisła k-1 & & AY158143 \\
\hline Euglena gracilis Klebs & unknown & X12890 & \\
\hline Euglena geniculata Dujardin & SAG $1224-4 b$ & AF289241 & \\
\hline Euglena geniculata Dujardin & SAG $1224-4 f$ & AY070252 & \\
\hline Euglena stellata Mainx & SAG 1224-14 & AF289244 & \\
\hline Euglena tristella $\mathrm{Chu}$ & SAG $1224-35$ & AF289246 & \\
\hline Euglena viridis Ehrenberg & SAG $1224-17 d$ & AF289248 & \\
\hline
\end{tabular}

SAG, Sammlung von Algenkulturen Pflanzenphysiologisches Institut der Universität Göttingen, Germany; UW, Department of Plant Systematics and Geography of Warsaw University, Poland; CCAP, Culture Collection of Algae and Protozoa, UK. 


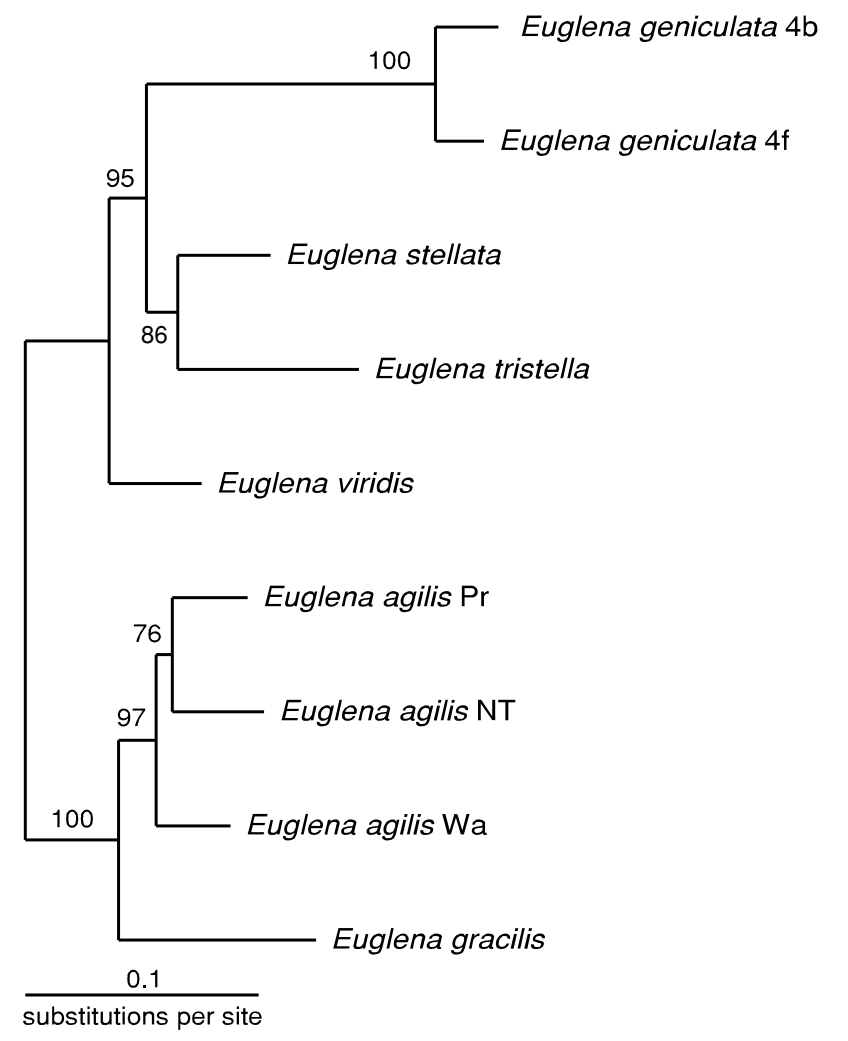

Fig. 1. Phylogenetic tree of $16 \mathrm{~S}$ rDNA of several euglenoid species, including three representative clones of E. agilis, obtained by Bayesian inference. The GTR+I+G model of sequence evolution (Tavaré 1986; Yang 1993) was used with likelihood parameters estimated by Markov Chains MonteCarlo method. Numbers at nodes show posterior probabilities of the tree bipartitions.

gion corresponding to LSU rDNA and some parts of ITS2. The parts corresponding to large regions of ITS 2 could be aligned only within the groups of very similar strains. Figure $2 \mathrm{a}$ shows the ClustalX guide tree generated with the default parameter values for gap penalties. Since there are many regions of uncertain homology in the alignment used for building this tree, it could not be considered as a true phylogenetic tree, rather a phenogram representing pair wise sequence similarity. However, it was shown that in case of ITS2, such a tree could reflect quite accurately the partitions between groups of divergent sequences (Hershkovitz and Lewis 1996).

The seven sequences form two groups consisting of sequences represented by clones with or without the ability to form mucus (Fig. 2a), when the whole length of the aligned sequences was used (462 nt). The first group, represented on Figure 1 by the NT clone, also contains the sequences of Pi and Go clones, all without the ability to form mucus. The group consists of sequences from $\mathrm{Wa}$ and $\mathrm{Pr}$ localities, represented on Figure 1, and additionally the sequences from Wi (substantial mucus) and Ko (minute mucus). Within the clones which are able to form mucilage, those with substantial mucus form a separate group, while clones forming a minute mucus branch first. When sites which could not be unambiguously aligned were eliminated in order to perform Bayesian maximum likelihood analyses, the strains did not form two well-defined groupings corresponding to the clones with and without ability to form mucus (Fig. 2b). The situation is somewhat similar when the sequence of E. gracilis was used as an outgroup

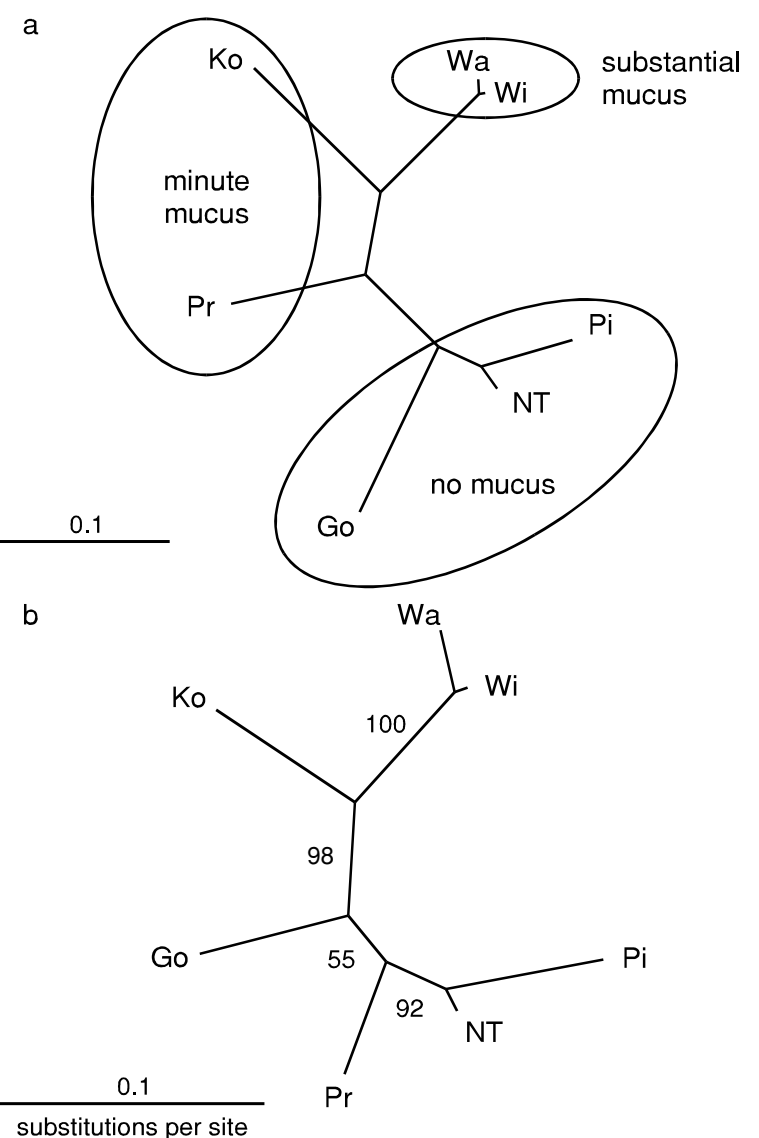

Fig. 2. Unrooted phenogram using 462 (a) and the phylogenetic tree of seven $E$. agilis clones, obtained by Bayesian inference (GTR $+\mathrm{I}+\mathrm{G}$ model of sequence evolution) using 277 sites (b). Numbers at nodes show posterior probabilities of the tree bipartitions.

(Fig. 3). The clones form two sister groups, one with the ability to form mucus and the other without that ability, and within the latter group the clones with minute mucilage branch of first, only on a phenogram when all sites were used for analysis (Fig. 3a). However, the portion of unambiguously aligned sites used for maximum likelihood analysis decreased further to 211 , resulting in lower posterior probabilities precluding inferring of real relationships between clones. Only two clones with substantial mucus form a well-defined clade.

\section{DISCUSSION}

Analysis of 16S rDNA (Fig. 1) shows that the three clones of E. agilis form a robust clade. The differences between them are similar to those between E. geniculata strains showing high morphological variability. Results of ITS2 sequence analysis are generally consistent with the indirect molecular probing (RAPD, RFLP) (Zakryś and Kucharski 1996; Zakryś et al. 1996) (Figs 2, 3). Taken together with earlier findings concerning morphology (microscopic observations and biometry) they indicate that different genetic clones of $E$. agilis coexist in natural populations, but genetic differences are not reflected in morphological characteristic, with the one possible exception of the ability to form a slimy envelope during cellular division in the state of non-motile palmella. Judging by differences in ITS2 sequences (Figs 2a, 3a) E. agilis clones seem to form two gro- 

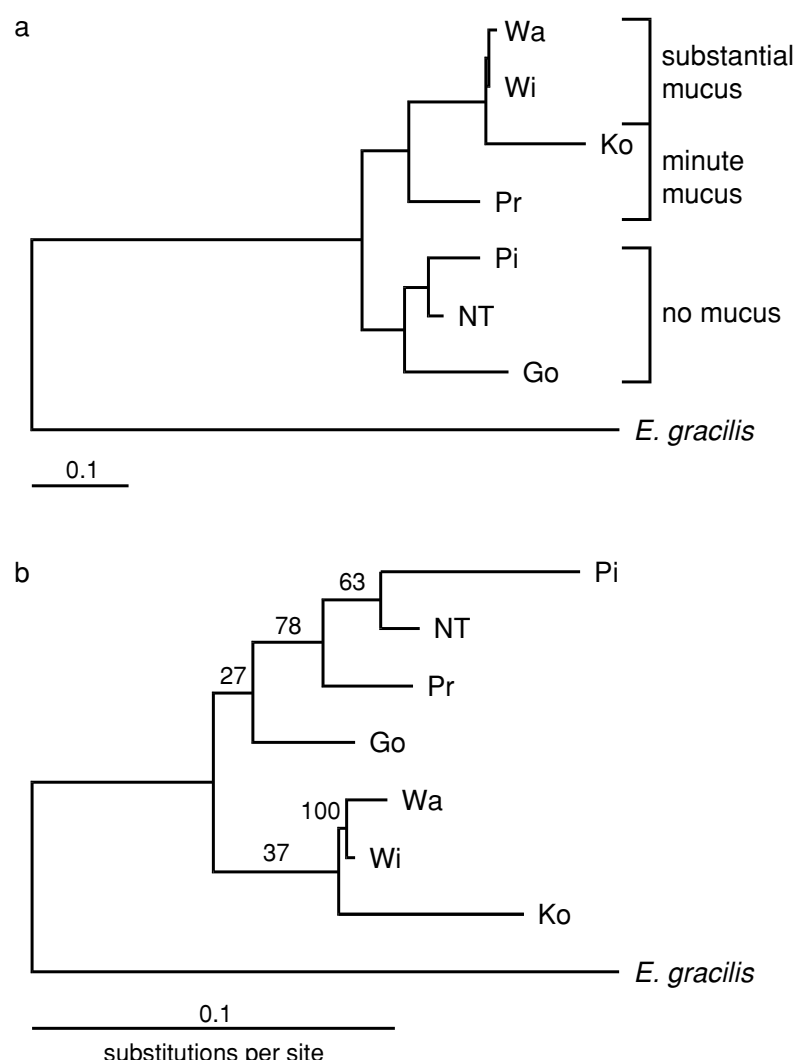

Fig. 3. Rooted phenogram using 475 (a) and the phylogenetic tree of seven $E$. agilis clones, obtained by Bayesian inference (GTR $+\mathrm{I}+\mathrm{G}$ model of sequence evolution) using 221 sites (b). Numbers at nodes show posterior probabilities of the tree bipartitions.

ups - non-slimy clones (Go, Pi, NT) and slimy clones (Wi, Wa, Ko and Pr). However, due to a weak phylogenetic signal in ITS2 sequences such grouping could not be confirmed with significant probabilities.

Evolutionary adaptation as formation of slimy envelope may be attributed to different survival strategy (Zakryś and Kucharski 1996). Euglenoids live in a highly variable environment such as small astatic bodies of water like puddles, ponds, ditches, drainage canals in which sudden changes of environmental conditions often take place. Some clones of E. agilis multiply very fast and expansively, giving up protection of their dividing stages (palmellas). Within a short time the population becomes too dense and survival stages are formed. Those which do not manage to finish that process before a reservoir they inhabit dries out, must die. Others clones invest more energy to protect their division stages at the expense of the rate of reproduction. However, surrounded by the thick layer of mucus palmellas are able to survive temporary periods of drought (Zakryś and Kucharski 1996).

The question arises whether it is desirable to erect a taxon based on the level of variance or form, which would take into account the differences at the morphological level (ability to produce a slimy envelope). In our view this is not warranted for three reasons:

1) the difference in mucus formation is manifested only at palmella stage, whereas E. agilis is identified in environmental samples in the flagellate stage (motile stage) hence it is not particularly useful in identifying the species,

2) the lack or the presence of this feature may be related merely to different life strategies, therefore this should be regarded as related to different ecological forms,
3) in spite of the relative high polymorphism between clones of E. agilis all of them form a well defined clade.

For these reasons we believe that a new reclassification of taxa in E. agilis group is not necessary and the proposition of Zakryś (1997) in the wake of the additional findings presented here should stay. The former study proposes to take as synonyms of Euglena agilis Carter four taxa in the rank of species (E. bichloris Schiller, E. bipyrenoida Prošk.-Lavr., E. nana Johnson and E. van-goori Deflandre), fourteen intraspecific taxa of the species $E$. agilis (var. apyrenoida Schiller, var. circumsulcata Schiller, f. coeruleoviridis Schiller, var. praeexcisa Schiller, var. varians Schiller) and E. pisciformis Klebs (var. minor Hansgirg, var. granulosa Playfair, var. piriformis Szabados, var. fallax Pringsheim, var. lata Pringsheim, var. mucronata Pringsheim, var. obtusa Pringsheim, var. procera Pringsheim, var. striata Pringsheim).

\section{ACKNOWLEDGEMENTS}

This work was supported by the State Committee for Scientific Research (KBN) Grant no. 3 PO4C 082 25. We thank Professor Dr. U. G. Schlösser, Sammlung von Algenkulturen (SAG), Göttingen, Germany for providing euglenoid strains and Dr. R. Triemer for his comments on the manuscript.

\section{LITERATURE CITED}

BUSSE I., PREISFELD A. 2002a. Phylogenetic position of Rhynchopus sp. and Diplonema ambulator as indicated by analyses of euglenozoan small subunit ribosomal DNA. Gene 284: 83$-91$.

BUSSE I., PREISFELD A. 2002b. Unusually expanded SSU ribosomal DNA of primary

osmotrophic euglenids: molecular evolution and phylogenetic inference. J. Mol. Evol. 55: 757-767.

BUSSE I., PREISFELD A. 2003. Systematics of primary osmotrophic euglenids: a molecular approach to the phylogeny of Distigma and Astasia (Euglenozoa). Int. J. Syst. Evol. Microbiol. 53: 617-624.

HERSHKOVITZ M.A., LEWIS L.A. 1996. Deep-level diagnostic value of the rDNA-ITS region. Mol. Biol. Evol. 13: 1276-1295 .

HUELSENBECK J.P., RONQUIST F., NIELSEN R., BOLLBACK J.P. 2001. Bayesian inference of phylogeny and its impact on evolutionary biology. Science 294: 2310-2314.

HUELSENBECK J.P., RONQUIST F. 2001. MRBAYES: Bayesian inference of phylogenetic trees. Bioinformatics 17: 754-755.

LEANDER B.S., FARMER M.A. 2000. Comparative morphology of the euglenid pellicle. I. Patterns of strips and pores. J. Eukaryot. Microbiol. 47: 469-479.

LEANDER B.S., FARMER M.A. 2001a. Evolution of Phacus (Euglenaceae) as inferred from pellicle morphology and SSU rDNA. J. Phycol. 37: 143-159.

LEANDER B.S., FARMER M.A. 2001b. Comparative morphology of the euglenid pellicle. II. Diversity of strip substructure. J. Eukaryot. Microbiol. 48: 202-217.

LEANDER B.S., TRIEMER R.E., FARMER M.A. 2001. Character evolution in heterotrophic euglenoids. Eur. J. Protistol. 37: 337-356.

LINTON E.W., HITTNER D., LEWANDOWSKI C., AULD T., TRIEMER R.E. 1999. A molecular study of euglenoid phylogeny using small subunit rDNA. J. Eukaryot. Microbiol. 46: 217-223. 
LINTON E.W., NUDELMAN M.A., CONFORTI V., TRIEMER R.E. 2000. A molecular analysis of the Euglenophytes using SSU rDNA. J. Phycol. 36: 740-746.

MARIN B., PALM A., KLINBERG M., MELKONIAN M. 2003. Phylogeny and taxonomic revision of plastid-conteining Euglenophytes based on SSU rDNA sequence comparisons and synapomorphic signatures in the SSU rRNA secondary structure. Protist 154: 99-145.

MILANOWSKI R., ZAKRYŚ B., KWIATOWSKI J. 2001. Phylogenetic analysis of chloroplast small-subunit rRNA genes of the genus Euglena Ehrenberg. Int. J. Syst. Evol. Microbiol. 51: 773-781.

MONTEGUT-FELKNER A.E., TRIEMER R.E. 1997. Phylogenetic relationships of selected euglenoid genera based on morphological and molecular data. J. Phycol. 33: 512-519.

MOREIRA D., LÓPEZ-GARCIA P., RODRIQUEZ-VALERA F. 2001. New insights into the phylogenetic position of diplonemids: $\mathrm{G}+\mathrm{C}$ content bias, differences of evolutionary rate and a new environmental sequence. Int. J. Syst. Evol. Microbiol. 51: 2211-2219.

MÜLLNER A.N., ANGELER D.G., SAMUEL R., LINTON E.W., TRIEMER R.E. 2001. Phylogenetic analysis of phagotrophic, photomorphic and osmotrophic euglenoids by using the nuclear 18S rDNA sequence. Int. J. Syst. Evol. Microbiol. 51: 783-791.

NUDELMAN M.A., ROSSI M.S., CONFORTI V., TRIEMER R.E. 2003. Phylogeny of Euglenophyceae based on small subunit rDNA sequences: taxonomic implications. J. Phycol. 39: 226-235.

PAGE R.D.M. 1996. Treeview: An application to display phylogenetic trees on personal computers. Comp. Appl. Biosci. 12: 357-358.

PREISFELD A., BERGER S., BUSSE I., LILLER S., RUPPEL H.G. 2000. Phylogenetic analyses of various euglenoid taxa (Euglenozoa) based on 18S rDNA sequence data. J. Phycol. 36: $220-226$.

PREISFELD A., BUSSE I., KLINGBERG M., TALKE S., RUPPEL H.G. 2001. Phylogenetic position and inter-relationships of the osmotrophic euglenids based on SSU rDNA data, with emphasis on the Rhabdomonadales (Euglenozoa). Int. J. Syst. Evol. Microbiol. 51: 751-758.

SCHNARE M.N., COOK J.R., GRAY M.W. 1990. Fourteen internal transcribed spacers in the circular ribosomal DNA of Euglena gracilis. J. Mol. Biol. 215: 85-91.

SCHLÖSSER U.G. 1994. SAG - Sammlung von Algenkulturen at the University of Göttingen. Cataloge of strains 1994. Bot. Acta 107: 113-187.
TAVARÉ S. 1986. Some probabilistic and statistical problems on the analysis of DNA sequences. Lect. Math. Life Sci. 17: 57-86.

THOMPSON J.D., HIGGINSi D.G., GIBSON T.J. 1994. Clustal, In: improving the sensitivity of progressive multiple sequence alignment through sequence weighting, positions-specific gap penalties and weight matrix choice. Nucleic Acids Res. 22: 4673-4680.

THOMPSON M.D., COPERTINO D.W., THOMPSON E., FAVREAU M., HALLICK R.B. 1995. Evidence for the late origin of introns in chloroplast genes from an evolutionary analysis of the genus Euglena. Nucleic Acid Res. 23: 4745-4752.

THOMPSON J.D., GIBSON T.J., PLEWNIAK F., JEANMOUGIN F., HIGGINS D.G. 1997. The ClustalX windows interface: flexible strategies for multiple sequence alignment aided by quality analysis tools. Nucleic Acids Res. 24: 4876-4882.

VAN DE PEER Y., ROBBRECHT E., de HOOG S., CAERS A., de RIJK P., de WACHTER R. 1999. Database on the structure of small subunit ribosomal RNA. Nucleic Acids Res. 27: 179$-183$.

YANG Z. 1993. Maximum likelihood estimation of phylogeny from DNA sequences when substitution rates differ over sites. Mol. Biol. Evol. 10: 1396-1401.

ZAKRYŚ B., KUCHARSKI R. 1996. Microevolutionary processes in Euglena pisciformis. Genetic drift or adaptation? Algol. Stud. 81: 23-37.

ZAKRYŚ B., KUCHARSKI R., MORACZEWSKI J. 1996. Genetic and morphological variability among clones of Euglena pisciformis based on RAPD and biometric analysis. Algol. Studies 81: 1-21.

ZAKRYŚ B. 1997. On the identity and variation of Euglena agilis Carter (=E. pisciformis Klebs). Algol. Stud. 86: 81-90.

ZAKRYŚ B. 1997a. The taxonomic consequences of morphological and genetic variability in Euglena agilis Carter (Euglenophyta): Species or clones in Euglena? Acta Protozool. 36: 157$-169$.

ZAKRYŚ B., MORACZEWSKI J., KUCHARSKI R. 1997. The species concept in Euglena in the light of DNA polymorphism analyses. Algol. Studies 86: 51-79

ZAKRYŚ B., MILANOWSKI R., EMPEL J., BORSUK P., GROMADKA R., KWIATOWSKI J. 2002. Two different species of Euglena - E. geniculata and E. myxocylindracea (Euglenophyceae) are virtually genetically and morphologically identical. J. Phycol. 38: 1190-1199. 